\title{
TRADUÇÃO E ÉTICA: A PROBLEMÁTICA DA RETROCONVERSÃO
}

\begin{abstract}
Marie Helene Catherine Torres ${ }^{1}$
1-Universidade Federal de Santa Catarina, Florianópolis, Santa Catarina, Brasil/

$\mathrm{CNPq}$
\end{abstract}

Antes de mais nada, gostaria de mencionar que abordo o tipo de texto traduzido a seguir, isto é, um relato de viagem, sob o prisma da Ecotradução, termo que emprego pela primeira vez em português num texto escrito e que crio aqui a partir do inglês ecotranslation e do francês, éco-traduction. Desenvolverei em outro momento mais oportuno e propício a teoria da ecotradução aplicada à literatura brasileira traduzida, mas já posso adiantar que a ecotradução faz referência a todas as formas de pensamento e prática de tradução que se envolvem conscientemente nos desafios da mudança do meio ambiente induzida pelo homem (Cronin, 2017). Ainda à luz da ecoliteratura, a ecotradução concerne aos textos (literários no que me ocupa) que traz de uma forma ou de outra a natureza como tema, personagem, reflexão. A ecotradução apreende a tradução da relação entre a natureza e a literatura em diversos contextos culturais e examina em que medida a ficção e/ou a poesia deram um lugar essencial à natureza e às relações antrópicas com o meio ambiente.

A noção de exploração e descobrimento do ambiente natural sendo a temática principal de relatos de viagem em geral, e deste em particular, tentei traduzir de modo a colocar a floresta Amazônica como foco narrativo central e a valorizar certa ética em relação à preservação na narrativa histórica da exploradora francesa sobre as relações orgânicas entre humano e natureza. 
Publicado em Bordeaux em $1861^{1}$, o relato de viagem a seguir, da autoria de Mme Langlet-Dufresnoy, intitulado em francês Quinze ans au Brésil ou Excursions à la Diamantine [Quinze anos no Brasil ou excursões em Diamantino], ocorreu de julho de 1837 (capítulo I) a agosto de 1852 (capítulo IV). Alexandrine Langlet-Dufresnoy é a primeira europeia a descer o rio Arinos (Potelet, 49; Broc, 187). O contexto histórico pode explicar, em parte, a vinda da viajante junto ao seu marido para o Brasil.

Segundo o professor do Departamento de Estudos Portugueses e Tradução da Universidade polonesa Jagiellonia, em Cracóvia, Jerzy Brzozowski (25), com a criação da corte portuguesa no Rio de Janeiro em 1808 e, acima de tudo, a restauração dos Bourbons em 1815, as relações franco-brasileiras mudaram de forma espetacular. Em 1808, o Brasil abriu seus portos para o livre comércio com os poderes amigos, inclusive a França. A literatura francesa conquistou a elite culta, com livros vindos cada vez mais numerosos por navios no Brasil. O ano de 1816 é particularmente importante para as relações franco-brasileiras, pois é o ano da chegada da missão artística francesa no Rio de Janeiro e de dois franceses cuja contribuição para o conhecimento do Brasil do século XIX foi decisivo: o escritor Ferdinand Denis, que ficará no Brasil até 1819, considerado como o iniciador dos estudos portugueses e brasileiros na França, e o naturalista AugustinCésar de Saint-Hilaire, que viajou nas províncias do Rio de Janeiro, Minas Gerais, Goiás, São Paulo, Santa Catarina e Rio Grande do Sul entre 1816 e 1822 .

Finalmente, após o reconhecimento da independência do Brasil em relação a Portugal em 1825, a França, por sua vez, reconheceu a independência do novo Império em 1826 e assinou com ele o Tratado de amizade, de navegação e comércio. O Brasil passa terra de imigração, graças ao decreto que permitiu que os estrangeiros adquiram terras aráveis.

${ }^{1} \mathrm{O}$ exemplar com o qual trabalhei para esta tradução inédita em português é do acervo digital da Biblioteca francesa Gallica.

Cad. Trad., Florianópolis, v. 41, no esp. 1, p. 174-184, jan/jul, 2021. 
Brzozowski (36) relembra ainda que, a partir da década de 1840, iniciaram as viagens na Amazônia e na província do Pará. A literatura de ficção prevalece sobre os relatos de viagem como por exemplo os romances de Emile Carrey dos anos 1856-1857. Brzozowski afirma ainda que o relato de viagem de Mme Langlet Dufresnoy, realizado na segunda metade da década de 1840, só é publicado em 1861, seguido, um ano depois, de um artigo do geógrafo Reclus na Revue des deux Mondes em 1862. Esperava-se um boom nas publicações depois de 1867, data da abertura da navegação na Amazônia para navios estrangeiros, boom que só acontecerá a partir da década de 1880, quando a Amazônia se tornou, de fato, incontornável.

Existe uma única biografia de Alexandrine Langlet-Dufresnoy, escrita por Gilbert Siou (77-90) onde encontrei dados da sua origem na Nova Aquitânia, em St Jean d"Angely, região de Bordeaux na França. Siou descreve a autora como uma viajante-aventureira que seguiu o marido até o Brasil a procura de ouro, diamantes e outras pedras preciosas ou semipreciosas. Por um lado, graças a essa biografia, pude desvendar o mistério de alguns topônimos citados pela autora no seu relato de viagem. Por exemplo, quando ela cita a pequena cidade de "Taillidoules", Siou situa o lugar em Bom Jardim na beira do Rio Iriri, que foi acrescentado na tradução. Por outro lado, os dados fornecidos por Siou não correspondem sempre àqueles fornecidos pela própria autora, como por exemplo, a data do embarque do casal Dufresnoy de São Paulo para Itabuna em 1819, o que é impossível, pois só chegaram no Brasil em 1837. Trato, portanto, a leitura e uso desta biografia com cautela.

Além da biografia de Siou, usei informações do próprio prefácio do livro assinado por Paul Le Gay que avisa o leitor que a autora não tem nenhuma "pretensão literária", mas que essa mulher se aventurou entre Rio de Janeiro e Diamantino, no Mato Grosso, enfrentando as estações, o clima, as doenças, os animais ferozes e os índios selvagens e, com uma "coragem viril", atravessou o Rio Amazonas. Ainda pretende que o leitor seja cativado e excitado pelo sofrimento alheio, sofrimento moral e de dores 
físicas da autora, no meio da floresta infestada de "cobras, tigres e outros animais".

De fato, Alexandrine Langlet se casou em 1836, com 16 anos, com Alexandre Dufresnoy, oficial de justiça, conforme o que ela afirma na primeira sentença no seu livro. Por dedução, acreditamos que ela nasceu em 1920. O casal embarcou na cidade de Le Havre, na França, em 06 de julho de 1837 no navio Achille, como o escreve no seu primeiro capítulo, e chegam no Rio de Janeiro, quarenta e nove dias depois, no dia 25 de agosto de 1837.

Uma primeira pesquisa rápida no Dictionnaire des Bâtiments de la Flotte de Guerre Française de Colbert à nos jours sobre o navio Achille nos levou a constatar que existiu um navio de guerra com o mesmo nome. Portanto, continuei a pesquisa na hemeroteca digital da BN, iniciando pelo Jornal do Commercio entre 1830 e 1839. Na edição 00187 (1) de 1837, na seção "Movimento do Porto", entrada no dia 24, encontrei a menção seguinte:

Havre - 49 d., Gal.Franceza Achille, 264 tons, M. Belliard, equip. 16: carga fazendas a Leuzinger; passags. Os Francezes Gustave Babin e sua mulher, Laurent Christin, Camille Beral, Jules Lecarpentier, Duboscq, J. Jacqueminot, Jean Drevon, Filippe Vernier, Jean Feron, Felix Martin, Numa Lenglet, Honoré Maintigneux, os suissos Jean Leuzinger, Jacques Joseph Clerc, o Alemão João Chumacher com sua família, e os sardos M.G. di Intra e Carlo Farinelli.

"Numa Lenglet" deve ter sido transcrito de forma errônea no lugar de "M. e Mme Langlet." Os dados do navio e do seu capitão mencionados por Alexandrine Langlet correspondem. $\mathrm{O}$ dia da entrada do navio é 24 de agosto, registrado no seu diário como sendo dia 25, o que deixa pensar que tripulação e passageiros demoravam a desembarcar no porto do Rio de Janeiro. Essas precisões se fazem necessárias porque a autora afrancesou quase todos os nomes próprios, antropônimos e topônimos no seu texto. Situar 
sua narrativa no tempo e no espaço parece indispensável para tentar descobrir o percurso que a autora seguiu na floresta amazônica e localizar saltos, cachoeiras, rios e cidades que atravessou.

O papel de um(a) tradutor(a) é, primeiramente, o de ter uma certa ética com a tradução, o texto traduzido devendo "reproduzir" ambiente, estilo, sentidos, poeticidade, dramaticidade etc. em relação ao texto de partida. O texto de Alexandrine Langlet-Dufresnoy foi escrito como um diário, ou seja, para ser supostamente lido somente pela própria autora do texto, sem grande eloquência nem cuidados estilísticos ou literários. Porém, uma vez publicado, este texto teve como público-alvo os franceses ou quem lia em francês na metrópole, o atestam as inúmeras referências ao exotismo e exuberância relativos à Amazônia e aos seus habitantes indígenas ao longo do texto-testemunha. A autora está deslumbrada pela floresta e pela fauna. Ela vai naturalizando o que vê ao tentar descrever, por exemplo, uma anta, como uma "espécie de bezerro com tromba como a do elefante".

Para Antoine Berman, a ética da tradução parte do texto "original”, o texto primeiro, em direção ao texto traduzido. Ser ético para o tradutor é ser ético para com a cultura de origem e, ao mesmo tempo, para com a cultura de chegada. Daí o meu questionamento sobre como seria ser ético com o leitor? O leitor do texto traduzido, no nosso caso, o texto em português traduzido a partir de um texto escrito em francês cujas referências toponímicas não correspondem com lugares conhecidos, ou cuja existência não consegue ser comprovada, merece uma atenção especial e ética por parte do tradutor. É pensando no leitor brasileiro que tomei algumas decisões que considero "éticas" no presente contexto. Decisões que, de repente, não tomaria na tradução de outro texto.

A questão da tradução de topônimos pode ser mais complexa do que parece. No texto em francês, a autora usa alguns topônimos para localizar sua viagem. No entanto, o nome que ela atribui às cachoeiras, rios e saltos são nomes afrancesados e transcritos a partir do que ela ouvia e entendia. A dificuldade para o (a) tradutor(a) é tentar descobrir a que corresponderia na cultura de partida um nome próprio 
pertencente à fauna, flora ou outra localidade transcrito, isto é, adaptado foneticamente na língua de chegada ou transliterando uma parte do "original". Essa retroconversão dos topônimos do francês para o português me levou a pesquisar sobre cada um, tomando a decisão, às vezes da não-tradução dos termos afim de manter uma certa "ética" não somente com o texto de partida, mas principalmente com o leitor brasileiro. Consegui identificar e localizar muitos topônimos, a partir de mapas hidrográficos da Biblioteca Nacional e dos arquivos do Estados do Mato Grosso e do Pará, como "Arinnes" para "Arinos", "Seira" para "Serra", "bourachandes" para "borrachudos", "Mareigne-en-grand" para "Grande Maranhão", "Mareigne-en-petit" para "Pequeno Maranhão", a cachoeira de "Saint Simon" para "São Simão", situada no rio Juruena.

A partir da biografia de Siou, consegui decifrar que "Saint-Allin" corresponde "foneticamente" a Santarém. Quanto à cidade de "Marseillo", o contexto da viagem de volta para Bordeaux, na França, que para em Marseilha, indica que esta é a cidade mencionada pela autora.

Outros topônimos não foram localizados por não reconhecer os locais na retroconversão do francês para o português como "Petra" (cidade? Porto? Rio?), a cachoeira de "Loupouny", o "Tetentin" (Tocantins?), "Taillidoules" (cidade?), "La Prohibe” (será a Proibida? Aldeia, vilarejo?), "La Brèche" (porto?), "Machalle, Bonnin et Péderive" (Bairros? Sítios? Cidades?). Estas últimas foram citadas pela autora ao comentar uma revolução que localizei como sendo a Insurreição Praieira (modo que escolhi traduzir) que ocorreu na cidade do Recife entre 1848 e 1849 (Carvalho). Nesses casos, optei por não repetir nomes sem referências na tradução.

Nos capítulos que traduzi, isto é, III e IV (o livro possui quatro capítulos), Alexandrine Langlet-Dufresnoy saiu de Diamantino no atual Mato Grosso, morou alguns anos em Cuiabá e navegou sobre o Rio Arinos sem que o leitor saiba, na maior parte do tempo, em que época do ano ou mesmo em que ano isso acontecia. O texto apresenta, portanto, certo hermetismo quanto aos trajetos e outras precisões históricas-temporais. Quando a autora se refere a cidades 
como "Couritisa" ou "Moerie", ou ainda ao rio "Sainte-Anne", a tradução "ética" não permite traduzir "Couritisa" e "Moerie", pois não foi encontrado nenhum vestígio histórico de supostas cidades chamadas de "Couritisa" ou "Moerie". Optei nesse caso pela não-tradução dos nomes das cidades por serem "inexistentes" em português sob essa grafia. Quanto ao rio "Sainte-Anne", trata-se do Rio Santana na região mato-grossense.

Quando a autora evoca a fruta de "taíb" com a qual pode-se produzir um licor vinhoso, ela se refere a uma fruta amazônica que pode ser transformada em bebida com gosto de vinho. Da polpa de frutas como açaí, abacaba, buriti e patuá pode-se produzir vinho. "Taíb" poderia corresponder ao açaí, pois se come com farinha de milho como especificado na narrativa. Se for mais licoroso, poderia se referir também à aguardente de cupuaçu ou de jambu, licor de camu-camu, de açaí, de chichuá. Optei por traduzir por açaí, não por ser uma fruta grande, como descrita no texto, mas sim por ser uma fruta que "pode" parecer fonologicamente com "taíb" e por ser principalmente uma fruta amazônica cuja cor se assemelha à cor do vinho e licoroso quando transformado em bebida (Guerreiro).

Outra fruta mencionada, é o "mouyar" que, segundo a autora, seria uma espécie de limão. Considerando que para uma francesa do início do século XIX, um limão é necessariamente amarelo, o tradutor deve procurar uma fruta parecida com limão siciliano. É a razão pela qual optei por conservar a ideia de fruta, de cor amarela, de origem amazônica e com "aproximação" fonológica. Traduzi por "maracujá” que vem do tupi "mara kuya” segundo o Dicionário de tupi-português (1987).

As referências às tribos ou nações indígenas são pouco inteligíveis, mesmo após ter consultado, entre outros textos, o Quadro Geral dos Povos. Entre os 256 povos catalogados, encontrei os índios Apiaka ou Apiaca que moravam em aldeias nas margens do rio Arinos, descrito por Langsdorff na sua expedição pelos rios Arinos e Juruena em 1828 (1997: 201-207). Pode ser esta última a referência aos índios que a autora menciona quando nomeia a nação "Géroine" perto de Salto Augusto ou os índios "Piarouracquoi" 
na região da cachoeira São Gabriel. Como a presença dos índios Apiaka é plausível em relação ao lugar e momento da expedição da autora, optei por traduzir por Apiaka.

No tocante aos índios "Tapouilles”, especulei, após consulta do site da Funai, que, como a autora tem tendência em afrancesar topônimos e antropônimos, se trata dos Tapayuna que ocupavam originalmente terras às margens do Rio Arinos, no Mato Grosso.

A nossa estratégia para a tradução das cachoeiras, pontes e rios varia conforme a identificação e geolocalização ou não dos topônimos. A Cachoeira dos Dois Gêmeos, que não localizei, foi traduzida literalmente; o rio "Leitterage", que conforme a autora se situa à margem esquerda da cidade de Maranhão, corresponderia ao "rio Mearim". As cachoeiras "Sainte-Aburse" e "Sainte-Elise" não foram localizadas nos mapas consultados e, portanto, não as nomeie na tradução.

A ponte "Dabourif" na cidade do Recife corresponde à Ponte do Recife, primeiro nome dado à Ponte Mauricio de Nassau e a "Villa d'Oligne" a Olinda conforme consulta ao Site do Governo do Estado de Pernambuco. Porém a ponte "Manquine" e a "Porte-de-chaux" não foram localizadas nos arquivos consultados sobre a cidade de Recife.

Os barcos que a autora pega ao longo do seu périplo são galeotas, vapores e outro bergantim. Procurando novamente nos artigos e anúncios dos jornais da época na hemeroteca da Biblioteca Nacional, descobri que o vapor "Impératrice du Brésil" era a barca "Imperatriz do Brasil" (Chaves, 91).

Segundo o texto, apesar das imprecisões de geolocalização, Alexandrine Langlet embarcou em Salvador para a cidade de Le Havre na França em 22 juin 1852 no navio Léoni que localizei na Hemeroteca da BN (Biblioteca Nacional) como sendo um bergantim francês cujo nome exato era "Jeune Léonie". Quanto ao "Lélie", a autora embarcou em seguida ao sair de Le Havre em direção a Bordeaux, supostamente por volta dos dias 29-30 de agosto de 1952. Embora não localizasse o nome do navio sendo um navio local francês, escolhi manter o nome em francês na tradução para o português. 
A questão da intraduzibilidade poderia ter tomado conta da nossa concepção de tradução, já que não consegui desvendar os referentes de muitos topônimos ou outros nomes próprios brasileiros na passagem para a cultura brasileira, que ironicamente deveria ser a origem de todos eles. Contudo, parti da premissa que qualquer texto pode ser traduzido, pois considero o texto traduzido como um outro texto, construído e constituído a partir de um texto preexistente, que lhe é, portanto, anterior, o texto de partida, no nosso caso o relato de viagem de Alexandrine Langlet-Dufresnoy.

\section{Referências}

Broc, Numa. Dictionnaire illustré des explorateurs et grand voyageurs français du XIX siècle. Ed. CTHS, vol.3 Amérique. Paris, 1999.

Brzozowski, Jerzy. Rêve Exotique. Images du Brésil dans la Littérature Française (1822-1888). Cracovie, Faculté de Lettres de 1»Université Jagellonne, 2001.

Carvalho, Marcus J. M. de. "Os nomes da Revolução: lideranças populares na Insurreição Praieira, Recife, 1848-1849”. Rev. Bras. Hist. v. 23 n ${ }^{\circ}$ 45, 2003. https:// www.scielo.br/scielo.php?script $=$ sci_arttext\&pid $=$ S0102-01882003000100009.

Carvalho, Moacyr Ribeiro de. Dicionário de Tupi (Antigo)-português. Salvador: Biblioteca Digital Curt Nimuendajú, 1987. http://etnolinguistica.wdfiles.com/ local--files/biblio\%3Acarvalho-1987-dicionario/Carvalho_1987_DicTupiAntigoPort_OCR.pdf.

Chaves, Cleide de Lima, De um porto a outro: a Bahia e o Prata (18501889). Dissertação de Mestrado, UFBA, 2001. https://ppgh.ufba.br/tesesdissertacoes?title $=\&$ field_autor_a_value $=\&$ field_ano_de_publicacao_ value $=\&$ field_modalidade_objetos_value $=$ All\&page $=4$. 
Cronin, Michael. Eco-translation. Translation and Ecology in the Age ofthe Anthropocene. London: Routledge, 2017.

FUNAI. http://www.funai.gov.br/index.php/comunicacao/noticias/4832-livrode-antropologa-reune-mitos-e-lendas-do-povo-tapayuna.

Guerreiro Isaac. "Conheça aguardentes e licores de frutas da Amazônia". Jornal Amazônia, 16/07/2016. http://amazonia.org.br/2016/07/conheca-aguardentes-elicores-de-frutas-da-amazonia/.

Hemeroteca Nacional Digital da Biblioteca Nacional do Rio de Janeiro. http:// bndigital.bn.br/hemeroteca-digital/.

Jornal do Commercio (RJ), edição 00187 (1) de 1837, seção "Movimento do Porto". http://memoria.bn.br/DocReader/DocReader. aspx $? \mathrm{bib}=364568 \_02 \&$ pasta $=$ ano $\% 20183 \&$ pagfis $=9226$.

Langlet-Dufresnoy, A. Quinze ans au Brésil ou Excursions à la Diamantine. Préface par M. Paul Le Gay. Bordeaux : imp . G . Chariol , 1861. https:// data.bnf.fr/10571081/mme langlet-dufresnoy/. Mapas : https://www.bn.gov.br/ acontece/exposicoes/2015/07/historica-cartographica-brasilis-biblioteca-nacional.

Potelet, Jeanine. Le Brésil vu par les voyageurs français, 1816-1840. Paris, L"Harmattan, 1993.

Povos Indígenas no Brasil. Quadro geral dos povos. https://pib.socioambiental. org/pt/Quadro_Geral_dos_Povos.

Roche, Jean-Michel. Dictionnaire des Bâtiments de la Flotte de Guerre Française de Colbert à nos jours. Toulon : Impr. Maury, 2005. http://www.netmarine.net/ livres/dico/tome1-a.pdf.

Silva, Danuzio Gil Bernardino da (Org). Os diários de Langsdorff, vol 3, 21 de novembro de 1826 a 20 de maio de 1828. Trad. Márcia Lyra Nascimento Egg et alii. Campinas: Associação Internacional de Estudos Langsdorff. Rio de Janeiro: Editora FIOCRUZ, 1997. Vol. 3. 
Siou, Gilbert. Les Célestes, Histoires de femmes. Ed. du désir, 2017. Site do Governo do Estado de Pernambuco. "O Recife, Histórias de uma cidade". http:// www.recife.pe.gov.br/cidade/projetos/historia/cap3/cap3-box5.html

Marie Helene Catherine Torres. E-mail: marie.helene.torres@gmail.com. https:// orcid.org/0000-0001-9263-0162. 